\title{
Pemberdayaan Perempuan melalui Kelompok Pengrajin Sulaman Bayangan di Barung-Barung Belantai Kabupaten Pesisir Selatan
}

\author{
Nor Tiara, Yusnanik Bakhtiar \\ Program Studi Pendidikan Pancasila dan Kewarganegaraan \\ Universitas Negeri Padang \\ Email : Nortiara288@gmail.com
}

\section{ABSTRAK}

Penelitian ini dilatar belakangi oleh adanya kelompok pengrajin Sulaman Bayangan yang menjadi pemberdayaan bagi kaum perempuan dalam meningkatkan pendapatan ekonomi keluarga. Perempuan harus bisa membuat sulaman agar mereka bisa mandiri dalam segi ekonomi dan tidak bergantung kepada suami. Tujuan penelitian ini adalah untuk mengetahui pemberdayaan perempuan melalui kelompok pengrajin Sulaman Bayangan di Barung-Barung Belantai Kabupaten Pesisir Selatan. Jenis penelitian ini adalah kualitatif dengan menggunakan metode deskriptif. Pemilihan informan dilakukan dengan teknis purposive sampling dengan informan penelitian sebanyak 15 orang informan. Jenis data yang terdiri dari data primer dan data sekunder, dikumpulkan melalui observasi, wawancara dan studi dokumentasi. Teknik menguji keabsahan data menggunakan triangulasi dan teknik analisis data melalui reduksi data, penyajian data dan penarikan kesimpulan. Hasil penelitian menunjukkan bahwa pemberdayaan perempuan melalui kelompok pengrajin Sulaman Bayangan terbagi menjadi 2 bagian yaitu pemberdayaan perempuan yang dilakukan oleh ketua kelompok pengrajin Sulaman Bayangan dan yang dilakukan oleh tim pelaksana pengabdian masyarakat dari Universitas Negeri Padang. Adapun faktor pendukung pada pelaksanaan pemberdayaan perempuan melalui kelompok pengrajin Sulaman Bayangan di Barung-Barung Belantai adalah alat praktek yang cukup mendukung dan lokasi Sulaman Bayangan dekat dengan tempat wisata puncak mandeh sehingga membuat sulaman ini mudah dikenal banyak wisatawan. sedangkan faktor penghambat pelaksanaan pemberdayaan perempuan melalui kelompok pengrajin Sulaman Bayangan di Barung-Barung Belantai yaitu seperti masalah pemodalan, masalah SDM/pengrajin Sulaman Bayangan dan masalah pemasaran. Dapat disimpulkan bahwa pemberdayaan perempuan dapat dilakukan dengan memfasilitasi, sosialisasi, pelatihan, diskusi, pembinaan serta penyuluhan motivasi dan pelatihan menyulam pada pengrajin Sulaman Bayangan.

Kata Kunci: Pemberdayaan Perempuan, Sulaman, Sulam Bayang

\section{ABSTRACT}

This research is motivated by the existence of a group of Sulaman Bayangan craftsman who are empowering women to increase family economic income. Women must be able to make embroidery so that they can be independent in economic terms and not depend on their 
husbands. The purpose of this study was to determine the empowerment of women through the Sulaman Bayangan craftsman group in Barung-Barung Belantai Kabupaten Pesisir Selatan. This type of research is qualitative using descriptive methods. The selection of informants was done by purposive sampling technique with 15 informants as research informants. Types of data consisting of primary data and secondary data, collected through observation, interviews and documentation studies. The technique of testing the validity of data uses triangulation and data analysis techniques through data reduction, data presentation and drawing conclusions. The results showed that the empowerment of women through the Sulaman Bayangan craftsman group was divided into 2 parts, namely the empowerment of women carried out by the head of the Sulaman Bayangan craftsman group and carried out by the community service implementation team from Padang State University. The supporting factors in the implementation of women's empowerment through the group of Sulaman Bayangan craftsman in Barung-Barung Belantai is a fairly supportive practice tool and the location of the Sulaman Bayangan is close to Puncak Mandeh. In addition, the inhibiting factors for the implementation of women's empowerment through the group of Sulaman Bayangan craftsman in Barung-Barung Belantai are such as capital problems, HR problems / Sulaman Bayangan craftsmen and marketing problems. It can be concluded that the empowerment of women through the group of Sulaman Bayangan artisans is carried out by facilitating, socializing, training, discussion, coaching as well as counseling motivation and training to embroider the Sulaman Bayangan craftsman.

Keywords : Women Empowerment, Sulaman, sulam Bayang

This work is licensed under the Creative Commons Attribution-ShareAlike 4.0 International License. (2019 by author and Universitas Negeri Padang.

\section{PENDAHULUAN}

Pemberdayaan masyarakat adalah suatu kegiatan empowering masyarakat dengan memberikan motivasi dan dorongan kepada masyarakat agar mampu menggali potensi dirinya dan berani bertindak memperbaiki kualitas hidupnya. Pemberdayaan merupakan langkah awal dimana kegiatan masyarakat yang berorientasi kepada peningkatan kesejahteraan kehidupan masyarakat tersebut akan berlangsung. Kegiatan pemberdayaan ini dilakukan untuk:

(1) menumbuhkan kesadaran masyarakat tentang pentingnya usaha mereka dalam membebaskan diri kebodohan dan dari upah kerja yang rendah,

(2) membantu masyarakat untuk bisa hidup berorganisasi secara bersama agar dapat menjajaki berbagai peluang peningkatan akses terhadap pemberdayaan.

Menurut Mardikanto, Totok \& Soebianto, Poerwoko (2015:61) pemberdayaan adalah serangkaian kegiatan untuk memperkuat dan mengoptimalkan keberdayaan (dalam arti kemampuan atau keunggulan bersaing) kelompok lemah dalam masyarakat, termasuk individuindividu yang mengalami kemiskinan. Menurut Suharto (2010:59-60), tujuan utama pemberdayaan adalah memperkuat kekuasaan masyarakat, 
khususnya bagi kelompok lemah yang tidak punya keberdayaan baik karena kondisi internal (misalnya persepsi mereka sendiri) maupun karena kondisi eksternal (misalnya ditindas karena struktur sosial yang tidak adil).

Pemberdayaan perempuan merupakan upaya yang dilakukan untuk meningkatkan kemampuan perempuan dalam memperoleh akses dan kontrol terhadap sumber daya dalam seluruh aspek kehidupan. (Kemensos, 2011:11). Sedangkan menurut (Kemensos, 2012:13), pemberdayaan kaum wanita adalah aktivitas refleksi, suatu proses yang mampu diisiasikan dan dipertahankan hanya oleh agen atau subjek yang mencari kekuatan atau penentuan diri sendiri (self-determination).

Penelitian terdahulu yang menjadi acuan dalam penelitian ini yaitu, yang pertama skripsi Siti Fatimah (2018) berjudul Pemberdayaan Perempuan melalui Kelompok Wanita Tani Sambal di Nagari Talang Maur Kecamatan Mungka Kab. Lima Puluh Kota. Pemberdayaan ini mampu menciptakan kondisi masyarakat khusus perempuan menjadi berdaya dalam upaya meningkatkan perekonomian masyarakat dan kesejahteraan keluarga. Dalam skripsi Estri Alia (2016) dengan judul Pemberdayaan Perempuan Warga Binaan Sosial A melalui Keterampilan Menjahit di Panti Sosial Bina Karya (PBSK) Provinsi Daerah Istimewa Yogyakarta. Pemberdayaan yang dilakukan ini sangat baik karena mampu menambah keterampilan dan pengetahuan yang baru bagi warga binaan, baik dari yang tidak menjahit menjadi bisa sehingga dapat mengubah keadaan ekonomi Warga Binaan Sosial A melalui Keterampilan Menjahit di Panti Sosial Bina Karya (PBSK) Provinsi Daerah Istimewa Yogyakarta.

Selanjutnya dalam skripsi Rizka Wulandhani (2015) yang berjudul Pemberdayaan Perempuan melalui Kelompok Batik Tulis Lanthing dada Ibu Rumah Tangga di Gunting Gilangharjo Pandak. Pemberdayaan ini dapat merubah aktivitas ibu rumah tangga yang awalnya hanya mengurus keluarga saja setelah adanya pemberdayaan tersebut aktivitas ibu rumah tangga mulai berubah. Saat ini mereka telah mempunyai aktivitas membatik dan telah menjadikan ibu rumah tangga mandiri dan tidak bergantung sepenuhnya pada suami dalam memenuhi kebutuhan seharihari.

Bedanya kajian terdahulu dengan penelitian saya ialah, penelitian saya lebih fokus pada bagaimana pelaksanaan pemberdayaan perempuan melalui kelompok pengrajin Sulaman Bayangan yang dilakukan oleh masyarakat di Barung-Barung Belantai Kab. Pesisir Selatan dengan tujuan untuk meningkatkan kesejahteraan perempuan dalam kehidupan bermasyarakat.

Peneliti menemukan masalah dalam upaya pemberdayaan perempuan yang dilakukan masyarakat seperti masih banyaknya perempuan usia produktif yang menyandang masalah ekonomi disebabkan kurangnya keterampilan terutama menyulam, sedangkan menyulam adalah salah satu mata pencaharian yang bisa membantu 
perempuan untuk menambah penghasilan keluarganya. Selain itu, faktor lain yaitu masih rendahnya tingkat pendidikan dan pengetahuan yang dimiliki oleh penduduk di Barung-Barung Belantai Kab. Pesisir Selatan, menyebabkan keinginan untuk maju dan berkembang dalam upaya memperbaiki tingkat pendapatan ekonomi keluarga belum ada. Hal ini sangat nampak dari aktivitas para perempuan di daerah ini yang hanya mengurus rumah tangga dan mengasuh anak, sehingga pendapatan ekonomi keluarga hanya tergantung pada suami. Selain faktor tersebut, kurangnya kesadaran dari para ibu rumah tangga dalam menggali potensi dan bakat yang dimiliki mengakibatkan keahlian dan keterampilan yang mereka miliki tidak berkembang.

Kegiatan pemberdayaan ini
yang sudah dilakukan untuk mengembangkan kerajinan Sulaman Bayangan ini, namun masih belum berjalan dengan baik salah satunya yaitu kegiatan sosialisasi yang dilakukan oleh ketua kelompok pengrajin Sulaman Bayangan dalam kegiatan ini tidak beberapa orang yang datang untuk ikut untuk dalam mengembangkan pengetahuan tentang sulaman bayangan. Hal ini menjadi para pengrajin sering kurang kreatif dalam membuat Sulaman Bayangan dengan model yang terbaru. Oleh karena itu perlu adanya upaya pemberdayaan perempuan melalui kelompok pengrajin Sulaman Bayangan di Barung-Barung Belantai. Kerajinan ini sudah dilakukan secara turun-menurun oleh orang tua mereka, hal tersebut merupakan salah satu kegiatan pendorong mereka untuk terus mengembangkan kerajinan Sulaman Bayangan ini. Ditambah lagi Barung-Barung Belantai sebagai nagari yang memiliki topografi yang berbukit-bukit dengan tingkat kesuburan tanah yang rendah, sehingga bidang pertanian kurang dapat membantu perekonomian masyarakat. Itulah sebabnya di daerah ini terdapat sentra-sentra Sulaman Bayangan baik yang berstatus pengrajin sulaman maupun yang sudah pada tingkat penjualan.

Adapun tujuan pemberdayaan perempuan melalui kelompok pengrajin Sulaman Bayangan adalah untuk meningkatkan kemandirian perempuan dan membantu pendapatan ekonomi keluarga, serta tercapainya kesejahteraan masyarakat. penelitian ini bermanfaat untuk kelompok pengrajin Sulaman Bayangan dan masyarakat dalam pelaksanaan pemberdayaan perempuan kedepannya untuk menjadi lebih baik dan lebih maju di Barung-Barung Belantai Kabupaten Pesisir Selatan.

\section{METODE PENELITIAN}

Jenis penelitian yang digunakan dalam melakukan penelitian ini adalah kualitatif dengan menggunakan metode deskriptif, karena peneliti berusaha membuat deskripsi, gambaran dan lukisan tentang suatu keadaan atau peristiwa sebagaimana adanya. Dengan penentuan lokasi penelitian di Barung-Barung Belantai Kecamatan Koto XI Tarusan Kabupaten Pesisir Selatan berdasarkan pertimbangan di latar belakang serta waktu, biaya dan tempat. Untuk informan penulis menggunakan teknik purposive sampling karena dianggap 
bahwa informan kunci yang benarbenar memahami persoalan yang terjadi. Informan penelitian ini adalah pengrajin sulaman bayangan sebanyak 10 orang, sedangkan informan sebanyak 5 ketua kelompok pengrajin Sulaman Bayangan, 2 tim pengabdian masyarakat dari UNP, 5 pengrajin Sulaman Bayangan dan 2 masyarakat sekitar tempat kerajinan Sulaman Bayangan. Jenis data dalam penelitian ini menggunakan data primer dimana data diperoleh dari hasil observasi dan wawancara di lapangan. Selanjutnya data sekunder dapat di peroleh dari hasil studi dokumentasi di lokasi penelitian. Kemudian sumber data dalam penelitian ini di dapatkan melalui informan penelitian. Teknik pengumpulan data dilakukan melalui observasi, wawancara dan studi dokumentasi. Untuk menguji keabsahan data dalam penelitian, penulis menggunakan teknik triangulasi sumber. Selanjutnya data yang diperoleh akan dianalisis melalui tahap reduksi data, penyajian data dan penarikan kesimpulan.

\section{HASIL DAN PEMBAHASAN}

Kelompok pengrajin Sulaman Bayangan terdiri dari 9 kelompok pengrajin, dengan nama kelompok yang berbeda-beda sesuai dengan nama yang diberikan oleh pemilik sulaman tersebut. Kelompok pengrajin Sulaman Bayangan yang paling banyak anggotanya yaitu Sulaman Bayangan ibuk Rozzalinda yaitu ada sekitar 150 orang pengrajin sulaman. Sulaman Bayangan Rozzalinda ini merupakan sulaman tertua di BarungBarung Belantai yaitu didirikan pada tahun 1986. Selain itu sulaman bayangan yang paling sedikit anggotanya yaitu Sulaman Bayangan kaligrafi yaitu hanya beranggotakan sebanyak 15 orang saja karena Sulaman Bayangan ini termasuk baru dibuka yaitu pada awal tahun 2017.

Pemberdayaan perempuan melalui kelompok pengrajin Sulaman Bayangan di Barung-Barung Belantai terbagi menjadi 2 bagian yaitu:

1) Pemberdayaan perempuan oleh ketua kelompok pengrajin Sulaman Bayangan

a. Memfasilitasi pengrajin sulaman

Upaya yang dilakukan pengurus dan anggota kelompok pengrajin Sulaman Bayangan dalam memfasilitasi para pengrajin Sulaman Bayangan yaitu dengan memberikan kesempatan kepada para pengrajin untuk belajar mengembangkan keterampilan menyulam melalui kelompok pengrajin Sulaman Bayangan. Fasilitas yang diberikan ketua kelompok pengrajin sulaman dalam kegiatan menyulam seperti meminjamkan alat-alat dan bahan yang diperlukan dalam membuat sulaman. Setelah selesai mengerjakan sulaman maka pengrajin akan mengembalikan alat yang digunakan dalam membuat sulaman kepada ketua kelompok pengrajin Sulaman Bayangan.

b. Sosialisasi

Ketua kelompok pengrajin Sulaman Bayangan melakukan kegiatan sosialisasi dalam melestarikan dan mengembangkan kerajinan menyulam dengan pemberian pelatihan menyulam dan mensosialisasikan secara langsung melalui forum-forum non formal misalnya PKK maupun rembug desa (musyawarah/rapat desa) yang dilaksanakan oleh kaum perempuan. Kegiatan sosialisasi di lakukan 1 bulan sekali di rumah ketua kelompok Sulaman Bayangan. 
c. Pertemuan rutin

Pertemuan rutin biasa dilakukan oleh kelompok pengrajin Sulaman Bayangan setiap 1 (satu) kali dalam seminggu. Pertemuan rutin dilakukan sebagai bentuk komunikasi antara anggota. Bentuk dari pertemuan tersebut adalah kegiatan arisan setiap minggu. Tujuannya untuk memperkuat hubungan antara anggota agar keutuhan kelompok tetap terjaga.

d. Pelatihan kepada para pengrajin yang baru bergabung

Bagi pengrajin yang baru bergabung di kelompok pengrajin Sulaman Bayangan, diberikan pelatihan secara singkat tentang teknik dasar menyulam oleh ketua kelompok sulaman tersebut. Fungsi dari kegiatan ini diharapkan dapat mengasah dan meningkatkan kemampuan menyulam pada para pengrajin yang baru bergabung. Kegiatan ini penting mengingat selama ini potensi menyulam yang sudah dimiliki oleh warga tidak tergali dan belum dikembangkan.

2) Pemberdayaan perempuan yang dilakukan oleh tim pengabdian masyarakat dari UNP melalui kelompok pengrajin Sulaman Bayangan

a. Metode Diskusi

Tim pelaksana pengabdian dari UNP melaksanakan diskusi dengan ketua kelompok sulaman, mengenai berbagai hal untuk mendukung jalannya kegiatan. Diskusi ini penting agar tujuan yang ditetapkan sesuai dengan yang diharapkan, misalnya mendiskusikan perilaku pengrajin selama ini dalam melakukan kerjasama, akan bermanfaat bagi pelaksanaan kegiatan pemberian motivasi. Kegiatan diskusi ini tentu sangat membantu ketua kelompok sulaman untuk mengatasi berbagai kendala-kendala yang dihadapi oleh para pengrajin sulaman dalam membuat sulaman, seperti ketua kelompok mengetahui apa saja hal-hal yang membuat para pengrajin malas membuat sulaman yang bermotif sulit, dan bagaimana cara supaya para pengrajin bisa santai dalam membuat sulaman sehingga mendapatkan hasil sulaman yang bagus.

b. Metode Pembinaaan

Tim pelaksana pengabdian masyarakat dari UNP memberikan suatu solusi kepada ketua kelompok pengrajin sulaman, yang pelaksanaannya nanti akan dilakukannya secara berulang-ulang sampai ketua kelompok sulaman betul-betul paham dan mengerti. Misalnya mengenai pembenahan adminstrasi dan keuangan usaha. Disini pemilik sulaman bersedia membenahi manajemen dan pembukuan demi kemajuan usahanya. Selain itu, mitra dan para pengrajin sulaman dibina jiwa kewirausahaannya. Ketua kelompok diberi pembinaan untuk membenahi Layout Shoroom (ruangan pamer produk) mereka agar menjadi lebih menarik, dan pembinaan cara melayani pelanggan dengan sopan dan ramah, sehingga mampu menarik hati pelanggan untuk membeli.

c. Metode Penyuluhan dan Pelatihan Menyulam

Tim pengabdian masyarakat dari UNP mengundang motivator untuk memberikan penyuluhan motivasi kepada pemilik usaha dan para pengrajin sulaman selalu bersemangat dalam bekerja, meningkatkan kreativitas dan mampu berinovasi agar dapat menghasilkan produk yang 
berkualitas dan banyak disukai oleh banyak konsumen agar dapat meningkatkan pendapatan perekomian masyarakat.

Para pengrajin Sulaman Bayangan di Barung-Barung Belantai ini diberi upah menurut tingkat kesulitan pekerjaannya. Makin rumit pengerjaan, makin besar upah yang mereka terima dari pemiliki sulaman. Untuk lebih jelasnya gaji pengrajin Sulaman Bayangan dapat dilihat pada tabel berikut:

Tabel 1. Data Gaji Pengrajin Sulaman Bayangan Di Barung-Barung Belantai Kabupaten Pesisir Selatan.

\begin{tabular}{|l|l|l|}
\hline $\begin{array}{l}\text { N } \\
\text { o }\end{array}$ & $\begin{array}{l}\text { Pekerjaan } \\
\text { Pengrajin }\end{array}$ & \multicolumn{2}{|c|}{ Gaji } \\
\hline 1 & Tukang Lukis & $\begin{array}{l}\text { Rp. 25.000,- } \\
50.000 / \text { helai }\end{array}$ \\
\hline 2 & $\begin{array}{l}\text { Penyulam/Pe } \\
\text { njahit }\end{array}$ & $\begin{array}{l}\text { Rp. } \\
150.000 / \text { helai }\end{array}$ \\
\hline 3 & Penjaga Toko & $\begin{array}{l}\text { Rp. } \\
300.000 / \text { minggu }\end{array}$ \\
\hline
\end{tabular}

Sumber: Data Primer Kelompok Pengrajin Sulaman Bayangan Tahun 2019

Berdasarkan data di atas dapat dilihat bahwa rata-rata gaji pengrajin untuk sehelai baju adalah $\mathrm{Rp} 80.000$,sampai Rp 150.000,- yang dapat mereka selesaikan dalam waktu satu minggu. Biaya desain untuk tukang lukis adalah $R p$ 25.000,- sampai dengan Rp 50.000,- per helai baju. Produk yang sudah jadi nantinya dijual dengan harga mulai dari $\mathrm{Rp}$ 275.000,- sampai dengan $\operatorname{Rp} 550.000,-$. Beberapa produk mukena yang bermutu bagus dengan nilai seni yang tinggi dijual dengan harga Rp 600.000,sampai Rp 800.000,- karena membutuhkan waktu yang lebih lama untuk membuatnya yaitu sekitar satu bulan.

Penelitian ini sesuai dengan skripsi Wulandhani
Pemberdayaan Perempuan melalui Kelompok Batik Tulis Lanthing pada Ibu Rumah Tangga di Gunting Gilangharjo Pandak bertujuan untuk meningkatkan kemandirian bagi ibu rumah tangga, meningkatkan pendapatan ekonomi keluarga, sehingga dapat membantu suami dalam memenuhi kebutuhan seharihari dan meningkatkan strata sosial dalam masyarakat. Begitu pula dengan adanya kegiatan tersebut telah mengubah aktivitas para ibu rumah tangga yang tadinya monoton hanya dirumah mengurus anak, dan memasak, setelah adanya program pemberdayaan tersebut aktivitas ibu rumah tangga mulai berubah, dimana saat ini mereka telah mempunyai aktivitas yang positif berupa keterampilan membatik yang sebenarnya keterampilan tersebut sudah dimiliki hanya saja tidak terasah dan tersalurkan.

Menurut Ginanjar Kartasasmita dalam Nepiana D (2003:65) memandang bahwa pemberdayaan sebagai upaya membangun diri dengan mendorong, memotivasi dan membangkitkan kesadaran akan potensi yang dimilikinya serta berupaya untuk mengembangkannya. Jadi kegiatan inilah yang dilakukan oleh ketua kelompok pengrajin Sulaman Bayangan dan tim pelaksana pengabdian dari UNP dalam memberdayakan perempuan di Barung-Barung Belantai Kabupaten Pesisir Selatan.

Pemberdayaan perempuan melalui kelompok pengrajin Sulaman Bayangan ini dilakukan sebagai upaya kepedulian terhadap ekonomi masyarakat dimana kegiatan ini dapat meningkatkan pendapatan kaum perempuan di Barung-Barung Belantai 
Kabupaten Pesisir Selatan. Fenomena yang ada sebelum adanya kelompok pengrajin Sulaman Bayangan seperti: aktivitas perempuan rata-rata ibu rumah tangga yang hanya mengurus keluarga dan bergantung pada suami. Pekerjaan suami yang mayoritas hanya petani, buruh tani dan tukang kayu, membuat ibu rumah tangga hanya pasrah pada keadaan terkait dengan pendapatan suami yang diperoleh dan tentunya belum mampu memenuhi kebutuhan sehari-hari.

Atas dasar fenomena itulah, maka diperlukan kepedulian dalam menggali potensi dan keterampilan bagi perempuan di Barung-Barung Belantai agar mereka dapat hidup layak, mandiri dan meningkatkan pendapatan ekonomi keluarga. Salah satunya melalui pemberdayaan perempuan melalui kelompok pengrajin Sulaman Bayangan. Perempuan di Barung-Barung Belantai sebagian besar memiliki potensi menyulam, karena pada dasarnya mereka telah memiliki keterampilan menyulam yang bersifat turuntemurun baik dari nenek moyang maupun orang tua mereka.

\section{KESIMPULAN}

Berdasarkan uraian hasil penelitian mengenai pemberdayaan perempuan melalui kelompok pengrajin Sulaman Bayangan di Barung-Barung Belantai Kabupaten Pesisir Selatan yang sudah peneliti jelaskan sebelumnya, maka dapat disimpulkan bahwa pemberdayaan perempuan melalui kelompok pengrajin Sulaman Bayangan terbagi menjadi 2 bagian yaitu pemberdayaan perempuan yang dilakukan oleh ketua kelompok pengrajin Sulaman Bayangan dan tim pelaksana pengabdian masyarakat dari UNP. Pemberdayaan yang dilakukan oleh ketua kelompok pengrajin Sulaman Bayangan yaitu seperti memfasilitasi, sosialisasi, pertemuan rutin dan pelatihan kepada warga yang baru bergabung. Sedangkan pemberdayaan yang dilakukan oleh tim pelaksana pengabdian masyarakat dari UNP dilakukan melalui metode diskusi, metode pembinaaan, metode penyuluhan dan pelatihan menyulam.

\section{DAFTAR PUSTAKA}

Kemensos. 2011. Berdaya Bersama Perempuan Indonesia. Jakarta Pusat : Derektorat Jenderal Pemberdayaan Sosial dan Penaggulangan Kemiskinan.

Kemensos. 2012. Efektivitas Model Pemberdayaan Wanita Rawan Sosial Ekonomi. Yogyakarta : Balai Besar Pendidikan dan Pelatihan Kesehjahteraan Sosial.

Mardikanto, Totok \& Soebianto, Poerwoko. 2015. Pemberdayaan Masyarakat Dalam Perspektif Kebijakan Publik. Bandung : Alfabeta

Suharto, Edi. 2010. Membangun Masyarakat Memberdayakan Rakyat. Bandung : Refika Aditama.

Nepiana D. 2003. Proses Pemberdayaan Masyarakat Terasing Melalui Program Penyuluhan. Bandung.

Alia, Estri. 2016. Pemberdayaan Perempuan Warga Binaan Sosial A melalui Keterampilan Menjahit di Panti Sosial Bina Karya (PSBK) Provinsi Daerah Istimewa Yogyakarta. Skripsi : UNY 
288| Pemberdayaan perempuan..

Fatimah, Siti. 2018. Pemberdayaan Perempuan melalui Kelompok Wanita Tani Sambal di Nagari Talang Maur Kecamatan Mungka Kab. Lima Puluh Kota. Skripsi : ISP FIS UNP

Wulandhani, Rizka. 2015. Pemberdayaan Perempuan melalui Kelompok Batik Tulis Lanthing Pada Ibu Rumah Tangga di Gunting Gilangharjo Pandak. Skripsi : UNY. 